\title{
MULHERES DA ETNIA ANAMBÉ NA PRODUÇÃO DE FARINHA DE MANDIOCA
}

Nádile Juliane Costa de Castro (1)

Universidade Federal do Pará l Belém - PA - Brasil 
Este ensaio faz parte de uma experiência em campo realizada na aldeia da etnia Anambé, localizada no município de Mocajuba, no estado do Pará. O ensaio fotográfico tem por objetivo identificar a participação ativa das mulheres indígenas na produção da farinha de mandioca, que é o subproduto principal do cultivo desta espécie pelos povos indígenas da região (Figuras 1 a 8).

Os Anambé são, atualmente, 161 indígenas, de família linguística Tupi-Guarani, que tem perdido, ao longo das últimas décadas, seus elementos culturais, incluindo, nessas mudanças, casamentos interétnicos. Vivem em condições semelhantes à de sertanejos da região, incluindo a construção de casas com coberturas de palha, preservando alguns traços regionais, como a fabricação de peneiras, de cestos de cargas, de pilões, de arcos e flechas (PIB 2017). Para sua subsistência, praticam a caça, a pesca e cultivam roças, entre elas a de mandioca, que gera subprodutos como a farinha de mandioca, elemento que também serve de moeda de troca para adquirir produtos industrializados, por meio de fornecedor local.

O contexto da história desta etnia já demonstra a importância da cultura da mandioca na aldeia. O registro dessa atividade possibilita identificar as mulheres como força de trabalho, dando mostras quanto à divisão do trabalho dentro destes grupos quanto ao gênero, pois são elas as responsáveis pela produção da farinha. Há também a passagem de valores e de conhecimentos entre gerações, percebida pelas diversidades de faixas etárias registradas na produção da farinha de mandioca.

É evidente a participação ativa, a liderança e as singularidades das mulheres deste povo nessa atividade. Por certo, a produção da farinha de mandioca é um exemplo das relações de força de trabalho entre essas mulheres e de seu protagonismo. Sobretudo, a importância desse produto está na manutenção da tradição amazônica. A mulher da etnia anambé conduz com maestria as etapas da cadeia produtiva da farinha de mandioca.

\section{REFERÊNCIAS}

Povos Indígenas do Brasil (PIB). 2017. Anambé: modo de vida. Disponível em: https://pib. socioambiental.org/pt/povo/anambe/48. Acesso em: 20 nov. 2017. 


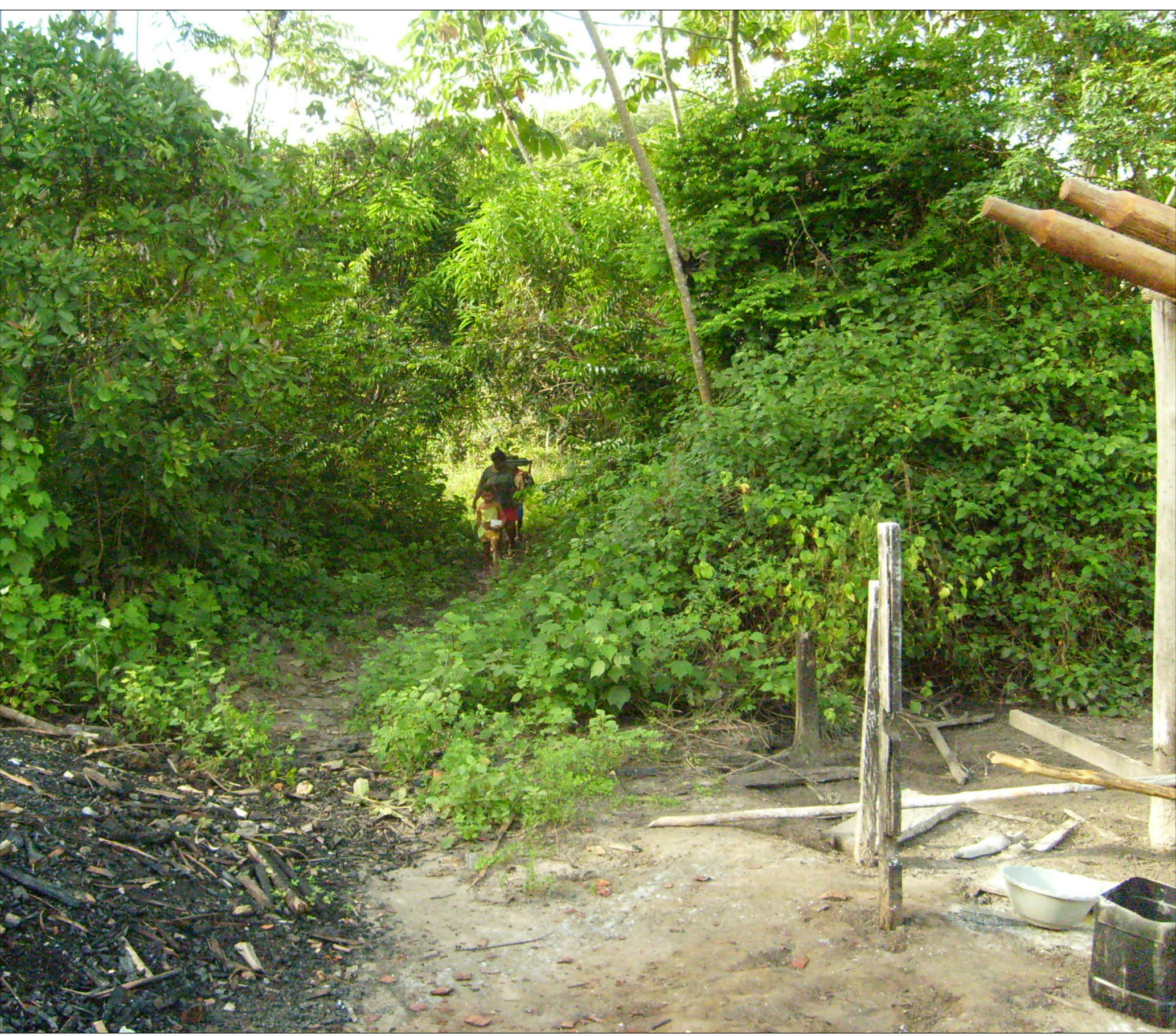

Figura 1 - A aldeia Anambé possui uma casa de farinha conjunta para todas as famílias do local que possuem acesso pela mata primária circundante às casas. As mulheres, no dia da produção, com todas as gerações, lideram a produção da farinha de mandioca. A imagem é do entorno da casa de farinha. Foto: Nádile Juliane Costa de Castro (2008). 


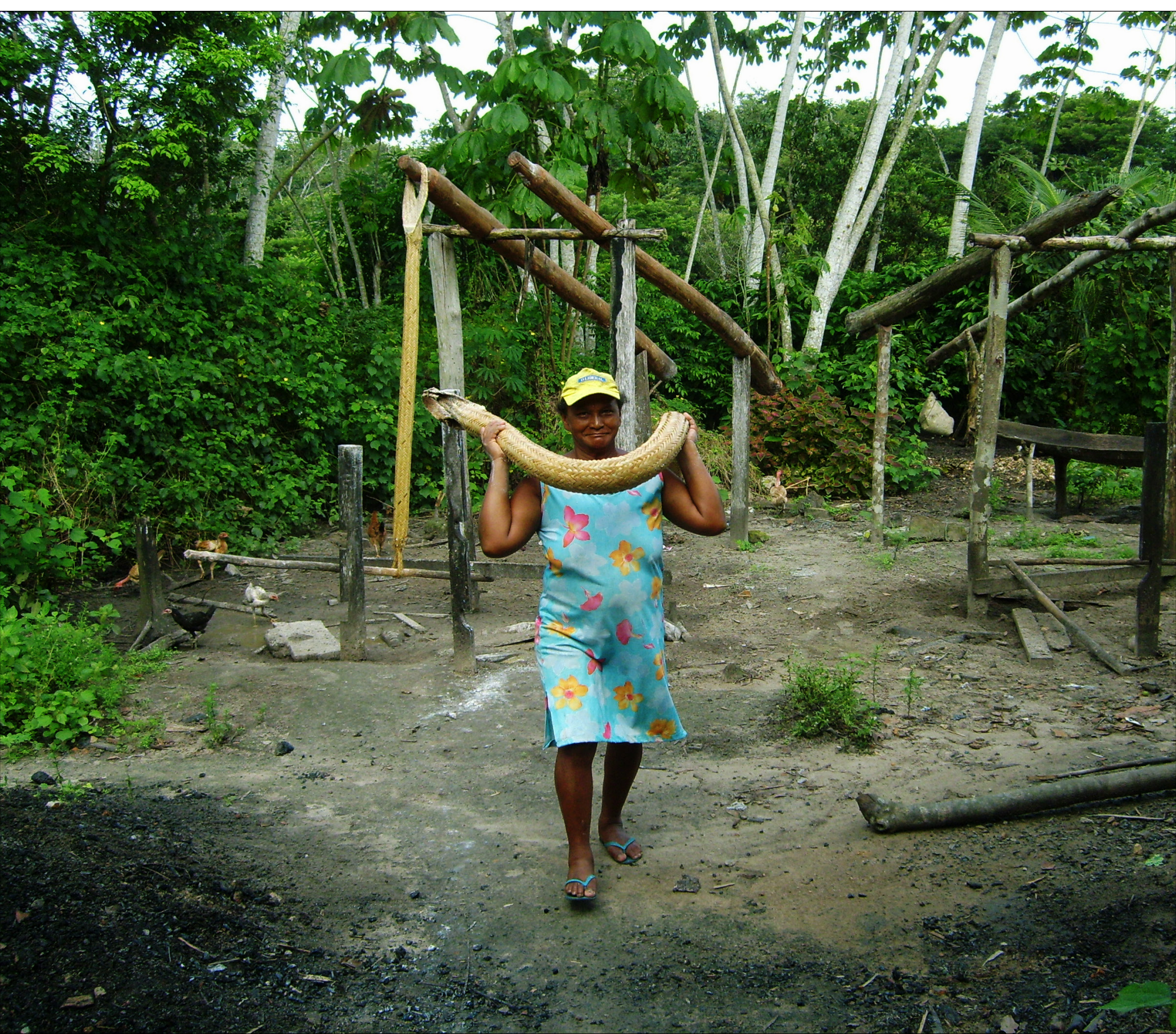

Figura 4 - Retirada do tipiti pós-prensa da massa de mandioca e extração dos subprodutos: goma e tucupi. Foto: Nádile Juliane Costa de Castro (2008). 


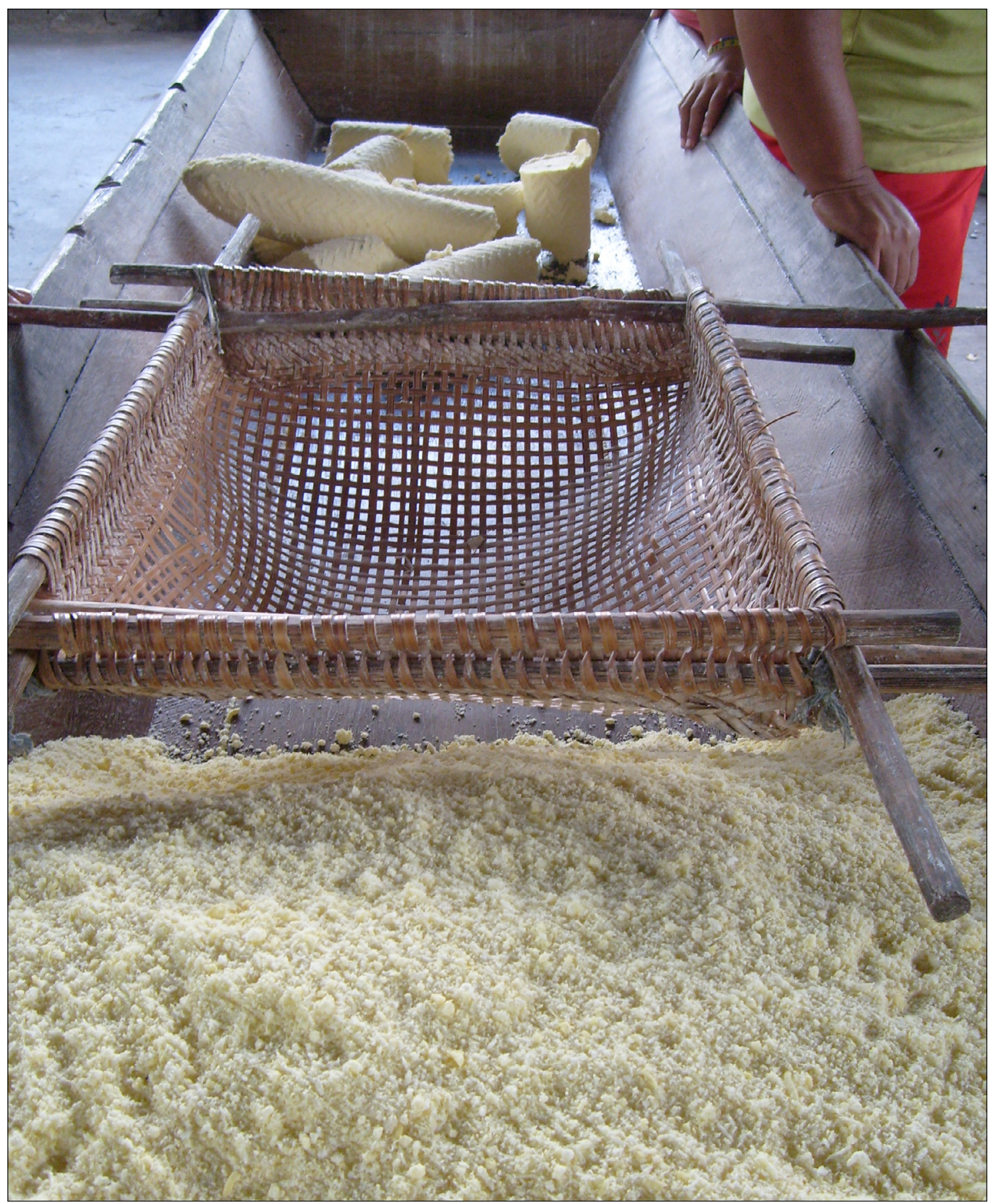

Figura 5 - Indígena da etnia Anambé peneirando a farinha de mandioca. Foto: Nádile Juliane Costa de Castro (2008). 


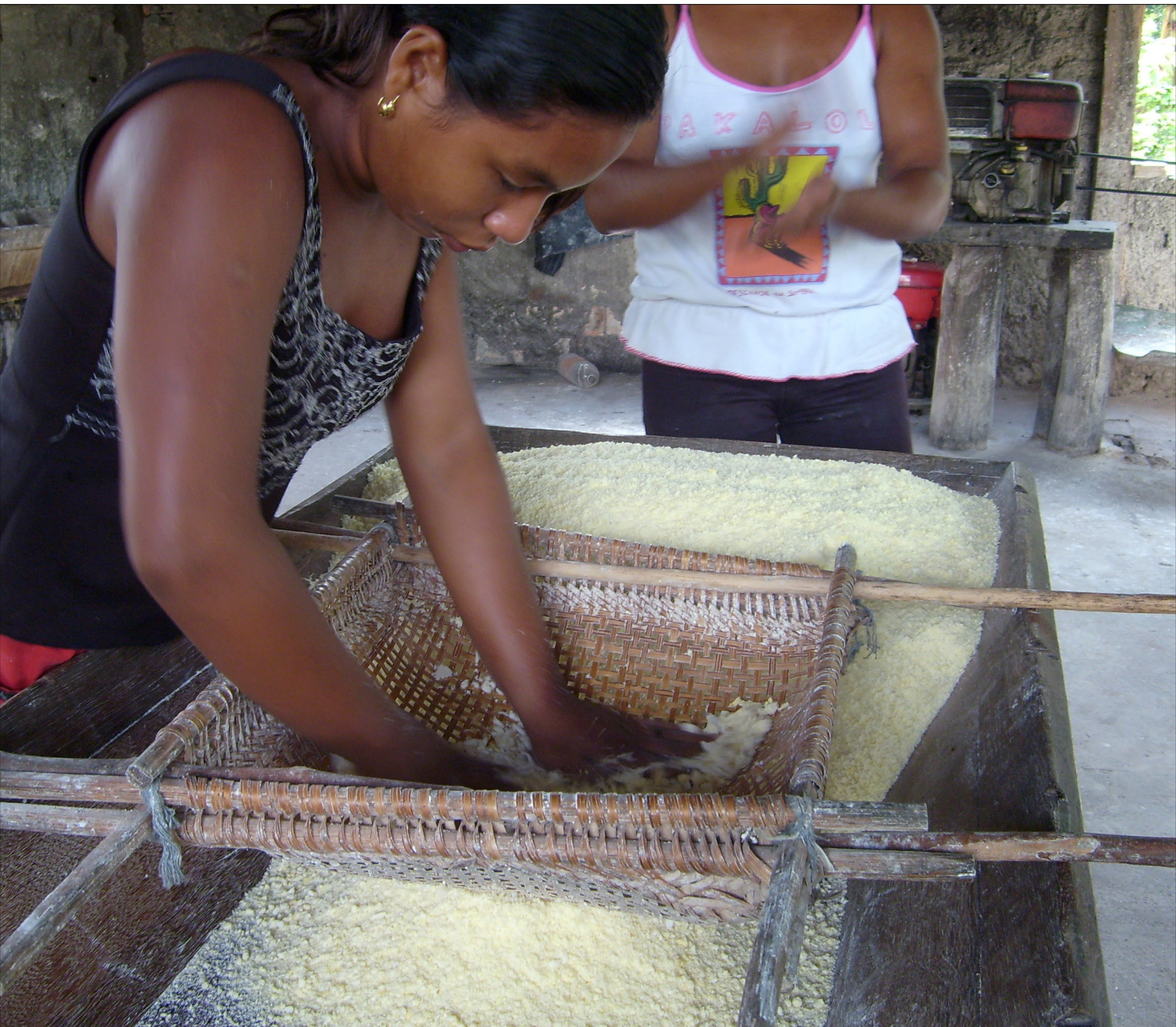

Figura 6 - Peneira de palha produzida pela etnia e farinha de mandioca peneirada. Foto: Nádile Juliane Costa de Castro (2008). 


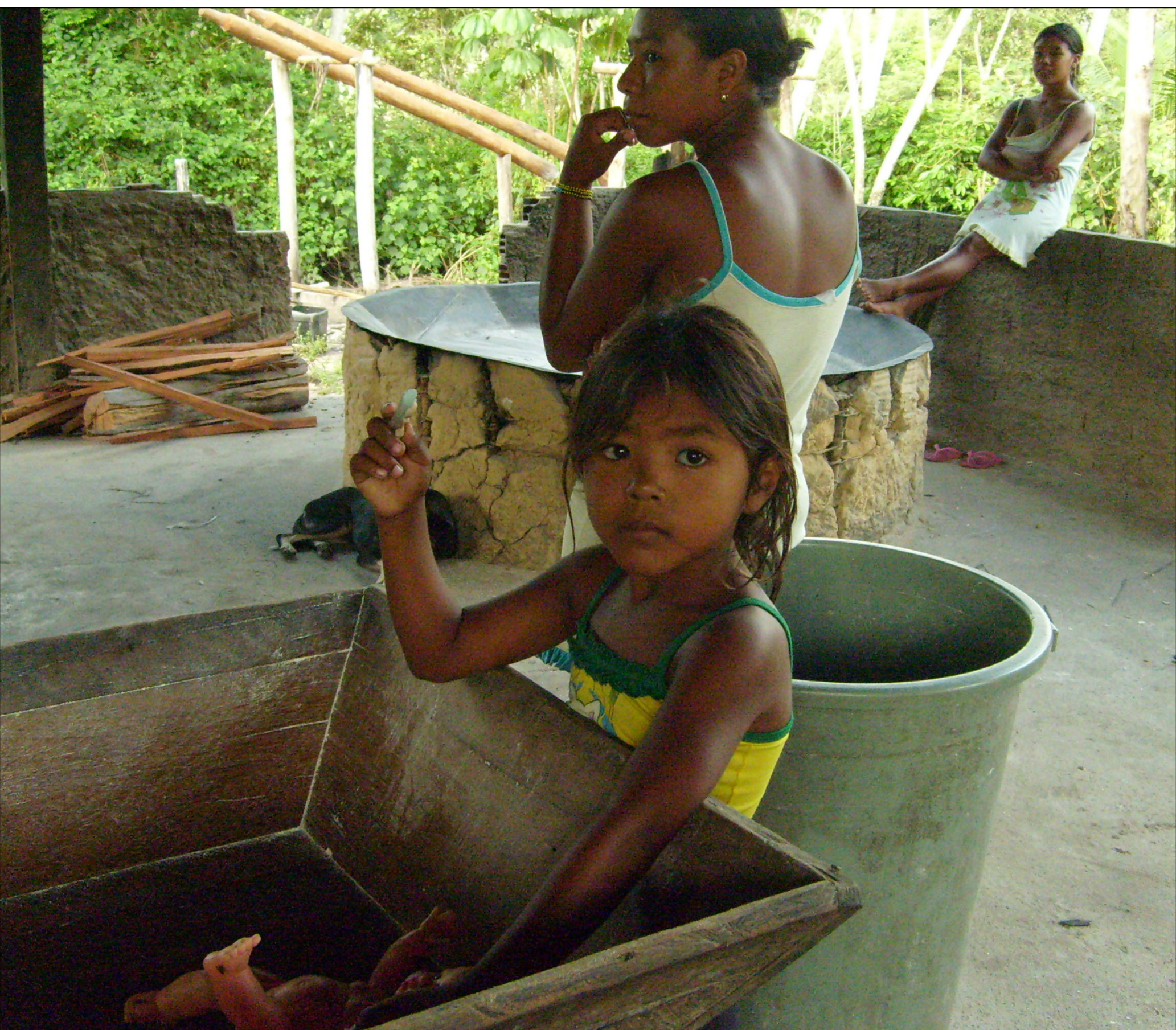

Figura 7 - Mulheres de várias gerações entre caixa de peneira e forno artesanal com base de argila. Foto: Nádile Juliane Costa de Castro (2008). 


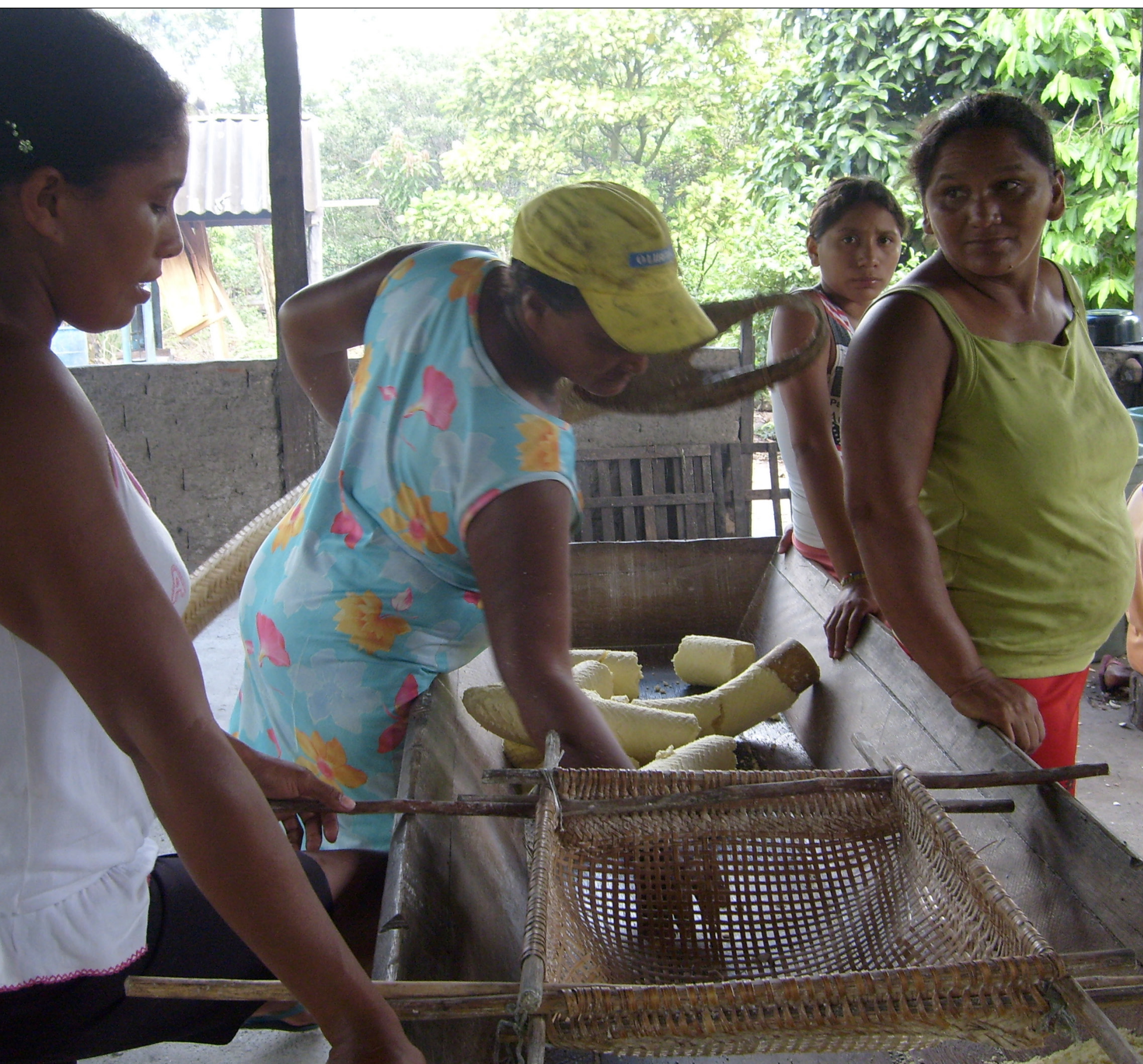

Figura 8 - As diversas gerações de mulheres da etnia Anambé na produção artesanal da farinha de mandioca. Foto: Nádile Juliane Costa de Castro (2008). 